\section{Ethical Lingua}

Journal of Language Teaching and Literature

ISSN 2355-3448 (Print)

ISSN 2540-9190 (Online)

Volume 4, Number 2, August 2017

pp. $120-126$.
Issued by Program Studi Pendidikan Bahasa dan Sastra Indonesia Fakultas Keguruan \& IImu Pendidikan, Universitas Cokroaminoto Palopo

Jalan Latammacelling 19, Palopo, Sulawesi Selatan, Indonesia 91921

\title{
Analysis of Phase Structure Realization in Classroom \\ Discourse: A Study of Systemic Functional Linguistics
}

\author{
Suparman and Charmilasari \\ suparman@uncp.ac.id | charmilasari@uncp.ac.id
}

Universitas Cokroaminoto Palopo, Indonesia

\author{
Accepted : 14 March 2017 \\ URL : : http://journal.uncp.ac.id/index.php/ethicallingua/article/view/624
}

\begin{abstract}
This study aims at describing the phase structure of classroom discourse in SMAN 1 Palopo. The research design employed is a qualitative study. The research location was SMAN 1 Palopo in which the population of the current study was classroom discourse in class X; while the sample were clauses that indicate the phase and interpersonal meaning of the teacher and the students who were selected using the purposive sampling technique. The source of data were the discourses in the biology, Physics and civic education classes. This study uses the theory of systemic functional linguistics to identify the clause phase structure consisting of phases and each sub-phase consists of 5 phases. Phase is used to transfer the science that aims to guide students to understand the material. Subphase comprises 33 phases which were divided into 4 static sub-phases and 29 dynamic sub-phases. System dominant mode shows the role of teachers in transferring science or knowledge expect information provided will be accepted by the students.
\end{abstract}

Keywords: phase structure, classroom discourse

\section{Introduction}

Language development is so fast and it requires us to continue to learn and develop our knowledge of the language. Language is a system of symbols that have meaning. Language has a major role in people's lives, especially to meet the needs of conveying messages, wishes, ideas, information and so on. Language is seen as a social semiotic system. Semiotic understanding of the cultural values and norms arise through social processes. The process is a form of social interaction using language as a medium. The forms of social processes can cover meetings, discussions, interviews, and classroom discourse. 
Discourses that refer to human social activity has a different context and objectives so that the language is expressed as a social practice. As the discourse of class certainly has a different context and with the purpose of political discourse, the discourse of lectures, discourses expected appointment or interview and other discourse.

Classroom discourse is the use of language associated with science as a means of communication that aims to distribute information in interaction in the classroom. Teachers and students interact with each other to achieve the learning objectives. Teacher transfers information and knowledge to students, and students receive information from teachers who subsequently respond to the teachers, and that is how reciprocal communication happen. Interaction between teachers and students in the classroom is a key condition to the process of teaching and learning. The purpose of the interaction of teaching and learning is not just transferring knowledge but inculcate attitudes and moral values in students.

The ability of discourse structures and interpersonal meaning teachers and students can help create the learning process dynamic and impressive. The ability of the situation is how, when, and the where clause was uttered able to determine the acceptability of the message. The use of modalities is the most important thing for a consideration or personal opinion of speakers to the message sent in interacting.

The information is transferred by the teacher in the form of text consisting of clauses which gradually shaped arrangement of verbal and realized through speech, sentence or proposition. Interpersonal meaning can realize the experience of a teacher and students to form good social relations in interaction in the classroom. Phase structure which is based on the context and meaning of interpersonal well designed can induce the thinking of students. For example what do participant phase as well as the modes and modalities of what should be done participant to help determine the acceptability of the message during the learning process.

Interpersonal meaning and structure of the phases used in the classroom not only to transfer knowledge, but also can open the minds of students, attracting attention, and motivate students. Therefore it is very important to conduct research on the structure of the phase by Gregory and interpersonal meaning by Halliday in classroom discourse. Analysis of interpersonal meaning and structure of the phase can determine the extent to which the role of the teacher in the learning process so that the educational goals can be realized well.

The general objective to be achieved in this paper, for example, applying the model approach Systemic Functional Linguistics in education, especially in the discourse of class by using the phase structure and interpersonal meaning. It also aims to provide full and thorough overview of the discourse in the classroom. Describing the realization of interpersonal meaning of discourse class at SMA Negeri 1 Palopo consisting of systems and modalities mode.

The terms of discourse and text are always confused one another. According to Jorgensen (2007: 1) the definition of discourse is a language that 
is arranged according to different patterns, followed by a speech-language users based on different social life. Sinars (2008: 7) considers the discourse is more focused on matters related to social factors.

Fairclough (1995: 6) states that the use of the language of discourse is seen as a form of social practice and discourse analysis is an analysis of how the text works in sociocultural practices. Such analysis requires attention to the shape, structure and organization of the text at all organization levels text: phonological, grammatical, and lexical at a higher level associated with exchange system (distribution turn to speak), the structure of the argument, and the generic structure.

Sinars (2008: 7) states that the discourse and text are two different things. Discourse is a social phenomenon, while the text is a linguistic phenomenon. Although they are different but the relationship between the two is the realization of the meaning of discourse gets its expression in the text.

Systemic Functional Linguistic Theory herein after abbreviated as SFL. SFL evolved since the 20th century at the time of Firth who leads a group called the linguistic community. Then in the 60 s the theory developed by M. A. K. Halliday. Halliday outlook of the language tends to be functional this is due to the orientation of development is always associated with the link element of situation / social (speakers, place, time, topic, etc.) (Purwo, 1990: 61). Systemic Theory is a theory of meaning as an option, in which a language or other semiotic system is defined as the arrangement between the network selections (Halliday, 1990: xiv).

The terms of linguistic theory (L) has two implications: (1) the analysis of discourse to put forward a theory of language that represents a particular theory and the research framework in discourse analysis to belong to and arise from an analysis called "linguistic" and cites the principles of the theory Systemic Functional Linguistics, (2) identify the phenomenon of discourse analysis implies that the basic approach interpretive language is semiotic, thematic and interdisciplinary. Further terms (F) in discourse analysis implies three things: (1) the functional realization of the system in the structures and patterns that regularly are horizontal and syntagmatic, (2) functions or meanings in language, and (3) the functions or meanings that exist in the profession and the level of varied dimensions in the language being studied. While systemic (S) oriented to three things, namely that the study was paying attention (1) the relationship of systemic and their choices in a wide range of possibilities in a network system of relationships and choices starting from general features to specific, vertical or paradigmatic (2) systems of meaning involved and interrelation in relation to the phenomena under investigation, and (3) systems underlying meaning behind, in front, below, above, and around or across the phenomenon under investigation (Sinar, 2003: 14-15).

Interpersonal meaning is an interpretation of the language in its function as a mutual exchange of information called 'language as activity' (Sinar, 2008: 47). Interpersonal meaning consists of two: the first concerns the type of interactions that occur and the type of goods being exchanged, the second concerns the position of the message spoken by the speaker (Butt et al., 2000: 86). 
Giving and receiving information is at the level of semantic meaning is most often at the level of lexicogrammar by asking questions or making statements. In contrast to the exchange of information, the exchange of goods and services involving the use of language to get something, either by offering to do it yourself or order others to do so. Asked for goods and services is on the level of semantic meaning is most often at the level of lexicogrammar by giving orders or instructions (Butt et al., 2000: 87-88).

\section{Methodology}

The type of research conducted by the researchers is a linguistic research that focuses on the field of Systemic Functional Grammar. In this study, researchers put more emphasis on the analysis of the structure realization phase and interpersonal meaning in classroom discourse. Therefore, the method used was descriptive qualitative method. This qualitative descriptive methods were supported by quantitative methods. Descriptive qualitative method was used because the data collected were mainly in the form of verbal utterances in interaction and learning. Researchers describe a systematic, factual, and accurate information on the phase structure and the use of interpersonal meaning in classroom discourse. Quantitative methods were used to support the descriptive statistical analysis to determine the percentage level of usage phases and sub-phases as well as the modes and modalities in the classroom discourse. Therefore the data were collected in the form of words in pictures and figures.

This research took place in SMA Negeri 1 Palopo and had been conducted in February 2017. The sample in this study consisted of clauses that indicated the phase and interpersonal meaning of teachers and students at SMA Negeri 1 Palopo. The sampling is done by purposive sampling technique with considerations and specific goals.

\section{Result and Discussion}

In this section was presented the description of research results in the form of results of analysis and discussion about: realization of phase structure in class discourse of SMA Negeri 1 Palopo.

\section{Realization of Class Discourse Phase Structure in SMA Negeri 1 Palopo}

In this section we will analyze the language aspect thoroughly to see how far the language works in the context of its use. In this section will be explained in detail of each stage that goes through when the discourse takes place in the classroom.

Results analysis of the phase structure of the class discourse that will be described below is expected to provide different models, styles, or patterns with other oral discourse structures so that they are easily recognizable by looking at their own character. 
In class discourse analysis, there were found some structures in class discourse at SMA Negeri 1 Palopo by using Halliday theory which then use Gregory discourse structure that is phase by making research of Sinar as reference in this research. Sinar divided the phases into two namely the phases and the sub-phases. The wealth of stages in a class discourse structure consists of 5 phases and 33 sub-phases. The results of the analysis and discussion can be seen as below.

\section{Phase}

The position of phase in the discourse of the SMA Negeri 1 Palopo class is not always the same. Frequency of occurrence of phase was seen from the number of sub-phase types that appear. This phase at the macro function level has a higher level of sub-phase that is at the level of micro function. Because the sub-phase that is at the level of micro function is part of the phase that is at the level of macro function.

\section{1) Phase of Understanding (PS)}

This phase covers the sub-phases of MSIm, Abs, Tgr, PM, Brd, Hmr, Puj, $S B k$, and SPt. All sub-phases include a phase of understanding as they can build understanding between teachers and students.

\section{2) Setting up of discourse (PW)}

PW encompasses the sub-phases of Pngr, FO, Ort and Pngt. The Pngr sub-phase is included in the PW phase because this phase is used by the teacher to direct the students into the material. FO is used by teachers to focus students' attention on the material. Ort used the teacher to introduce the material. Pngr is used by teachers to remind materials, ideas or concepts.

This phase type aims to provide the structure of class discourse and foster and anticipate the course of teaching and learning process, discuss what will be learned so that students can prepare and know the boundaries of the task to be done.

3) Substance (SU)

SU phase as the most important part in class discourse consisting of sub phase of Prt, Pnj, Def, MD, Cnth, Bnr, Crt. The sub-phase is included in the SU phase because this sub-phase that is on the academic target has the goal of transferring knowledge. SU phase is done by the teacher to guide students in understanding the material.

\section{4) Conclusion (SM)}

$B C$ as the phase used in class discourse. This phase consists of subphases of Rks, Png, Psn. These three sub-phases are included in the SM phase because $\mathrm{Rx}$ is used to infer material, information, ideas or concepts. Png aims to underline material, idea or information explanations. Psn which aims to give a message for the material delivered can be understood. At this conclusion phase the teacher concludes the material that has been discussed so that students better understand the material. 


\section{5) Evaluation (EV)}

The EV phase is used in class discourse which aims to evaluate, assess, and comment on the students' quality of responses to information. This phase is used by the teacher to see whether the learning has been successful or not. This phase is realized by sub-phase designation $(P n j k)$, elicit $(E / s)$, comments (kmtr), criticism (Krtk), acceptance (Pnr), answer (Jwb), assignment $(P T)$ and valuation $(P n)$.

Based on the results of the analysis of the 5 phases that emerged in the class discourse above, it can be seen that the most dominant phase emerges is the substance phase (SU) of 60 from WKB, 68 from WKF, and 53 from WKP. Phases with the number of occurrences under SU are PW of 35 from WKB, 48 from WKF, and 40 from WKP. The third sequence is the $45 \mathrm{EV}$ phases of WKB, 34 from WKF, and 25 from WKP. The fourth sequence is the PS of 7 from the WKB phase, 8 from the WKF phase, and 8 from the WKP phase. The presence of the substance phase (SU) shows that the teacher's most preferred academic objective is to transfer the knowledge and information realized by the subphases of Prt, Pnj, Def, Crt. In addition SU also serves to improve skills to students to be active in teaching and learning process realized by sub-phase MD, Cnth, Bnr.

The explanation of the above data can be supported by the percentage of phase structure described below.

Table 1. Percentage of Phase Structure

\begin{tabular}{lllllll}
\hline Phase / Macro & WKB & WKF & WKP & amount & $\%$ & Ranking \\
\hline Understanding (PS) & 7 & 8 & 8 & 23 & $5 \%$ & IV \\
Discourse Structuring (PW) & 35 & 48 & 40 & 123 & $28 \%$ & II \\
Substance (SU) & 60 & 68 & 53 & 181 & $41 \%$ & I \\
Conclusion (SP) & 5 & 2 & 3 & 10 & $2 \%$ & V \\
Evaluation (EV) & 45 & 34 & 25 & 104 & $24 \%$ & III \\
Number of Phases & 152 & 160 & 129 & 441 & $100 \%$ & \\
\hline
\end{tabular}

\section{Sub-phase}

The sub-phases found in the discourse of the SMA Negeri 1 Palopo class consist of 33 sub-phases: Direction (Pngr), Responding Greeting (MSIm), Focus $(F O)$, Absence, Justification (Bnr), Reminder (Pngt), Orientation (Ort), Statement (Prt), Designation (Pnjk), Elisitas (Els), Explanation (Pnj), Comments (Kmtr), Strikes (Tgr), Message (Psn), Summary (Rks), Criticism (Krtk), Encouraging (Drg), Comparing (Bnd), Reception (Pnr), Answer (Jwb), Affirmation (Png), Assignment (PT), Check, Assessment (Def.), Stories (Crt), Praise $(P u j)$, Example (Cnth), Humor $(H m r)$, Pray $(B D)$, Greetings Opener (Sbk), Salam Cover (Stp). The most dominant sub-phase of its appearance in 
the text is the statement (Prt) of $353(20 \%)$. The dominance of the sub-phases of the statement (Prt) is meaningful as the expression of the teacher to the information of science which is expressed in the form of ideas, concepts, and facts to the students.

\section{Conclusion}

The sub-phase structure contained in the discourse of the SMA Negeri 1 Palopo class consists of 5 phases and 33 sub-phases. The sub-phases are subdivided into static sub-phases consisting of 4 sub-phases namely SBk, STt, MSIm, and Brd. The dynamic sub-phase consisting of 29 sub-phases is Pngr, Fok, Pngt, Ort, Prt, Pnj, Def, MC, Bn, Rks, Png, Ps, Pnjk, Els, Kmt, Krtk, Pnr, Jwb, PT, Pnl, Pjn, MK, Tgr, PM, and Hmr. The most dominant phase structure found in the discourse of the SMA Negeri 1 Makassar class is the Substance Phase (SU), this phase is in the realm of science. The phase structure used in science transfer aims to guide students to understand the material so that students are not wrong in understanding by using their reasoning. The most dominant sub phase is the sub phase phrase (Prt) which aims to help students understand the views, ideas or concepts.

\section{References}

Butt. (2000). Using Functional Grammar: An Explorer's Guide. $2^{\text {nd }}$ Ed. Sydney: NCELTR, Macquarie University.

Cahyotomo, Anom. (2011). Role of Teachers in Education, (online), http://anomsblg.wordpress.com/

Christie, Frances. (2002). Classroom Discourse Analysis: A Functional Perspective. London: Continuum.

Sinars, Tengku Silvana. Phasal (2002). Lecturer and Experential Analysis of Discourse: A Systemic-Functional Analysis. Unpublished dissertation. (Online), http: //studentsrepo.um.edu.my/232/1/INTRO.pdf, accessed March 19, 2014).

Functional Approach). Terrain: National Library Press

Fairclough. (1995). Critical Discourse Analysis. London: Longman. 